\title{
EXPLORING THE OBSTACLES AND THE LIMITS OF SUSTAINABLE DEVELOPMENT. A THEORETICAL APPROACH
}

\author{
Paula-Carmen Roșca \\ Doctoral School of Economics, Faculty of Economic Sciences, University of Oradea, \\ Oradea, Romania \\ paula.rosca07@gmail.com
}

\begin{abstract}
The term "sustainable" or "sustainability" is currently used so much and in so many fields that it has become basically part of our everyday lives. It has been connected and linked to almost everything related to our living, to our lifestyle: energy, transport, housing, diet, clothing etc. But what does the term "sustainable" really mean? Many people may have heard about sustainable development or sustainability and may have even tried to have a sustainable living but their efforts might not be enough. The present paper is meant to bring forward a few of the limits of "sustainability" concept. Moreover, it is focused on revealing some arguments from the "other side" along with disagreements regarding some of the principles of "sustainable development" and even critics related to its progress, to its achievements. Another purpose of this paper is to draw attention over some of the issues and obstacles which may threaten the future of sustainability. The paper is also meant to highlight the impact that some stakeholders might have on the evolution of sustainable development due to their financial power, on a global scale.
\end{abstract}

Keywords: sustainability; development; limits; criticism; obstacles; disagreements.

JEL classification: Q01, Q50.

\section{Introduction}

The idea that the future should be a healthier and a better place for us and for the next generations is known as "sustainable development" and it embraces a growing acceptance that human actions have a serious and negative impact on our planet's ecosystems. The idea is not new and many researchers studied the phenomenon and a lot of debates took place over this topic, on a global scale, as there were many resistances and refusals along the way.

Sustainable development is a concept that integrates several areas that need to be rethought and refocused and involves economic development as much as other areas of human life and activity. After all, the primary aim is to find a way to reconcile the interests of economic development with the social and environment ones (Rojanschi, 2006, Badulescu et al, 2014).

One of the first researchers who was focused on studying sustainable development was Mahon Munasinghe who describes sustainable development as:

"a process for improving the range of opportunities that will enable individual human beings and communities to achieve their aspirations and full potential over a sustained period of time, while maintaining the resilience of economic, social and environmental systems. Thus, sustainable development requires both increases in adaptive capacity and opportunities for improving economic, social and ecological systems."

(Munasinghe, 2007) 
Also, he has created and presented at the 1992 Earth Summit in Rio, the triangle or the balance of sustainable development (Figure 1), all its three components being interdependent (Munasinghe, 2007; Munasinghe, 2010):

- Economic;

- Social;

- Environmental.

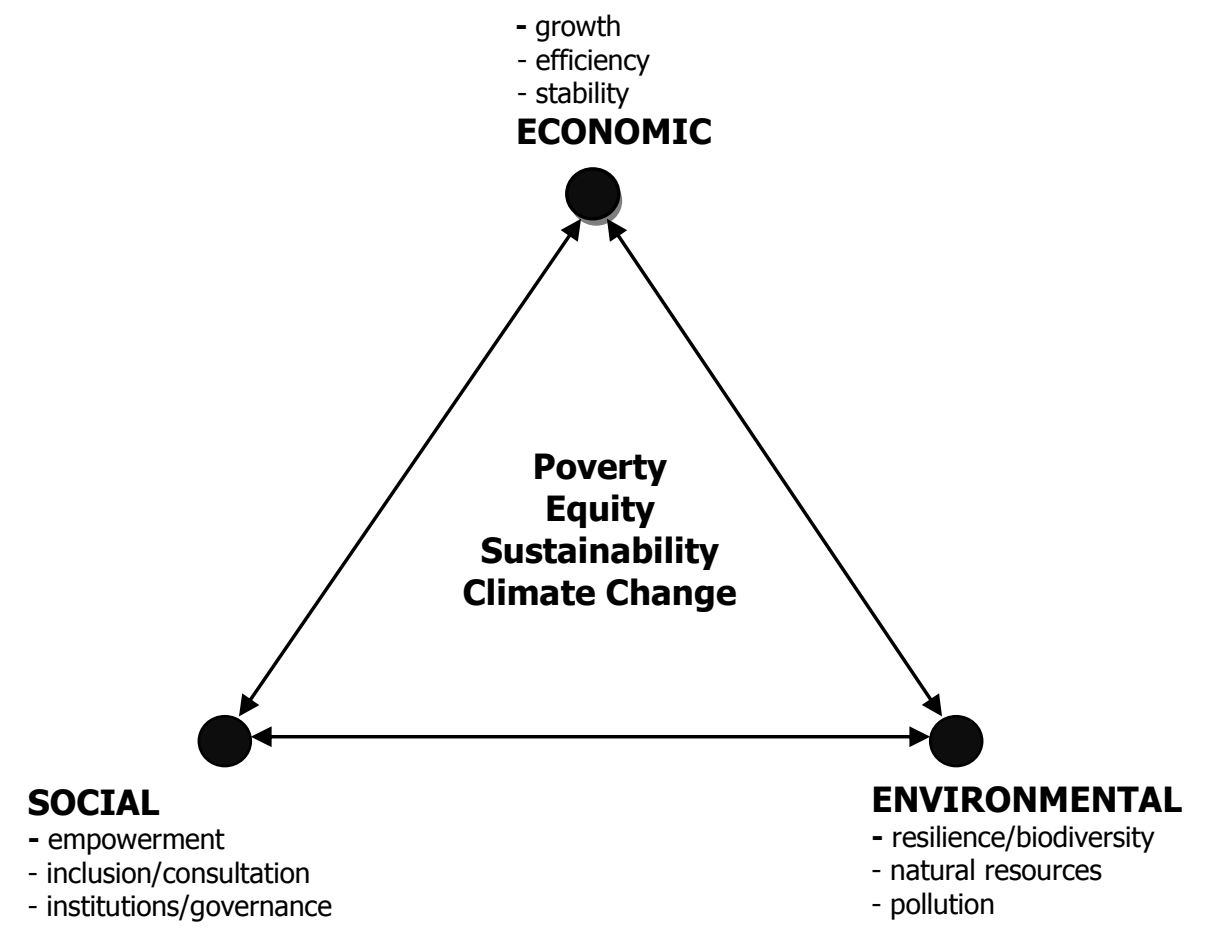

Figure 1: Sustainable development triangle

Source: Munasinghe, M. (2007) Sustainomics and sustainable development, [online] http://editors.eol.org/eoearth/wiki/Sustainable_development\#Sustainable_development_tri angle_and_balanced_viewpoint;

Long before the Earth Summit in Rio, in 1992, The United Nations (UN) Conference on the Human Environment took place in 1972, in Stockholm and it is considered to be the first cornerstone for identifying solutions to the problems faced by the population. According to Vogler (in Bâc, 2008:577) one of its contributions consists on the 26 principles included on the Declaration of the United Nations Conference on the Human Environment which became an important reference for the laws that were issued on environmental protection. The Conference represents the need for a common outlook and principles to guide the people in the preservation and enhancement of the environment (UNEP, 1972). It was accepted the connection between the environment and development even if the concept of "sustainable development" wasn't specifically mentioned on the conference documents (Badulescu, 2004; Bâc, 2008). 
Since then, other meetings, protocols and conferences were organized by UN on the topic of sustainable development:

- The Brundtland Report (Our Common Future) - 1987;

- Rio de Janeiro Earth Summit - 1992;

- Kyoto Protocol - 1997;

- The World Summit on Sustainable Development (Johannesburg) - 2002;

- United Nations Climate Change Conference (Copenhaga) - 2009;

- United Nations Conference on Sustainable Development, Rio+20 (Rio de Janeiro) 2012;

- United Nations Sustainable Development Summit (New York) - 2015.

The contributions of all the above meetings and conferences materialized in protocols, documents, agreements between states are often questioned by some authors and field experts. Despite all the debates, proposals and agreements that took place between states so far, there are several opinions according to which, sustainability, as approached during the last few decades has various drawbacks. The main criticisms are due to the results almost elusive in most areas of sustainable development. Thus, the future of sustainable development has been called into question. Our research is focused on presenting some of these critics and arguments against sustainability, in an attempt to highlight its limits. Our findings refer mainly to disagreements over some of the sustainability principles and critics regarding the vagueness of the concept or the lack of visible improvements throughout time. We also headed our research towards the limitations of the sustainability progress caused by obstacles like terrorism, population growth, lack of consensus regarding climate change etc.

\section{Research methodology}

The main purpose of the research is to identify the issues that have sparked criticism and the arguments underlying them. We focused on finding the main concerns regarding the improvements made until now, if we are on the right path or even if we need to be concerned about something.

The research is mostly a theoretical one and is based on other papers and studies written on this topic. The theoretical research is supported also by updated statistical information. For the statistical research we used as data sources, official information published on the webpages of organizations like World Bank, FAOSTAT, World Health Organization or publications like Fortune 500. The research covers a long period of time, including recent years (2015-2016) and presents comparisons and evolutions throughout time for several indicators (e.g.: global food consumption, people undernourished, comparisons between corporations and national economies regarding revenue/GDP etc.).

The findings of our research are split in four sections, starting with the criticism regarding the lack of progress and improvement and even the disagreements over the significance of this phenomenon. Moving forward, the second part presents aspects related to the vagueness of the concept while the last one lists a number of obstacles faced by the humanity in its way to a better future.

\section{Research findings}

\subsection{Disagreements over the sustainability principles}

Speth (2008) presents some of the limits of sustainability, through the eyes of the environment component. He states that although some improvement was registered, most of the threats linked to the environment that are acknowledged and extensively discussed during all the conferences and summits held on this subject, have worsened. He concludes that the results of more than two decades of international negotiations are deeply 
disappointing. Treaties and agreements and their associated protocols cannot do the necessary changes. Typically, these agreements are the easiest option for governments to act because they seem impressive but it does not bind to the objectives of the Treaties, objectives are often not followed by the requirements, goals and clear timetables. And even when there are targets and timetables, they are often inadequate and the means of execution are missing (Speth, 2008).

Regarding the disagreements, there are a few critics who argue against the principles of sustainable development. According to Beckerman (2002), future generations are likely to be much better off than the present generation due to the contribution of modern technology, which is rapidly increasing now and is more likely to remain so during the twenty-first century. He claims that we shouldn't ask the present generation to make sacrifices for future generations. The greatest favor that the present generation can do to the future one is to establish peace and security and to ensure the implementation of the principles of human rights and democracy.

Other critics believe that sustainable development can be damaging for the poor people. Thus, on the pretext of promoting sustainable development and environmental protection, rich countries are adopting protectionist policies by restricting imports of agriculture, forestry, and other products from developing countries. They also argue that, in the absence of concrete scientific evidence, environmentalists are recommending adopting precautionary principles, thus incurring a very high cost to control climate change, sea-level rise and ozone depletion which may or may not be significant threats to mankind. If such precautionary principles are not adopted, the resources can be utilized to satisfy the basic needs of the poor in developing countries (Rogers, Jalal, Bozd, 2008).

\subsection{Denial of exaggerated predictions}

Another criticism is addressed to the environmentalists who oftentimes show dramatic trends in negative environmental changes and make their points to invest more in the environment. Lomborg (2003) argues that real State of the World is much better and healthier than many environmentalists claim. In the same 2003 study, Lomborg criticized Ehrlich (1968) who stated: "the world will experience starvation of tragic proportion-hundreds of millions will starve to death". So, although the world population has doubled since 1961, the average calorie intake per capita has increased by $24 \%$ globally and $38 \%$ in developing countries. The statistics published by World Health Organization regarding food consumption at a global and regional level, reinforces Lomborg's opinion (Table 1).

Table 1: Evolution of global and regional food consumption (kcal per capita/day)

\begin{tabular}{|c|c|c|c|c|c|c|}
\hline Region & $\begin{array}{l}1964 \quad- \\
1966\end{array}$ & $\begin{array}{l}1974 \quad- \\
1976\end{array}$ & $\begin{array}{l}1984 \quad- \\
1986\end{array}$ & $\begin{array}{ll}1997 \\
1999\end{array}$ & 2015 & 2030* \\
\hline World & 2358 & 2435 & 2655 & 2803 & 2940 & 3050 \\
\hline Developing countries & 2054 & 2152 & 2450 & 2681 & 2850 & 2980 \\
\hline $\begin{array}{l}\text { Near East and North } \\
\text { Africa }\end{array}$ & 2290 & 2591 & 2953 & 3006 & 3090 & 3170 \\
\hline Sub-Saharan Africa & 2058 & 2079 & 2057 & 2195 & 2360 & 2540 \\
\hline $\begin{array}{l}\text { Latin America and the } \\
\text { Caribbean }\end{array}$ & 2393 & 2546 & 2689 & 2824 & 2980 & 3140 \\
\hline East Asia & 1957 & 2105 & 2559 & 2921 & 3060 & 3190 \\
\hline South Asia & 2017 & 1986 & 2205 & 2403 & 2700 & 2900 \\
\hline Industrialized countries & 2947 & 3065 & 3206 & 3380 & 3440 & 3500 \\
\hline Transition countries & 3222 & 3385 & 3379 & 2906 & 3060 & 3180 \\
\hline
\end{tabular}

*forecast 
Source: World Health Organization (2003) Diet, Nutrition and Prevention of Chronic Deseases [Online], Available: http://www.fao.org/docrep/005/AC911e/ac911e05.htm;

More than that, the statistical data of Food and Agriculture Organization of the United Nations (FAO) proves that starting from 2006, the number of undernourished people is decreasing in all regions including Asia and Africa (Table 2).

Table 2: Evolution of the number of people undernourished (millions) (3-year average)

\begin{tabular}{|l|c|c|c|c|c|c|c|c|}
\hline Region & $\mathbf{2 0 0 0 -}$ & $\mathbf{2 0 0 2 -}$ & $\mathbf{2 0 0 4 -}$ & $\mathbf{2 0 0 6 -}$ & $\mathbf{2 0 0 8 -}$ & $\mathbf{2 0 1 0 -}$ & $\mathbf{2 0 1 2 -}$ & $\mathbf{2 0 1 4 -}$ \\
\hline Africa & 210.2 & 214.6 & 214.3 & 213.6 & 217.6 & 218.3 & 221.4 & 230.3 \\
\hline Asia & 636.6 & 669.1 & 679.3 & 640.1 & 583.6 & 547 & 526.8 & 511.7 \\
\hline $\begin{array}{l}\text { Latin America and } \\
\text { the Caribbean }\end{array}$ & 60.4 & 55.5 & 50.3 & 44 & 40.3 & 38.3 & 36 & 34.3 \\
\hline Oceania & 1.3 & 1.4 & 1.4 & 1.3 & 1.2 & 1.3 & 1.4 & 1.4 \\
\hline World & 929.6 & 959.2 & 961.7 & 913.8 & 857.9 & 820.6 & 800.3 & 792.5 \\
\hline Total & 1890 & 1947 & 1949 & 1849 & 1733 & 1637 & 1597 & 1581 \\
\hline
\end{tabular}

http://www.fao.org/faostat/en/\#data/FS;

\subsection{The Limits and the Vagueness of the Concept}

Robinson (2004: 375) summarizes his three criticisms of sustainable development in the way it was debated so far, as: "vague, attracts hypocrites and fosters delusion".

Regarding the uncertainties, the author argues that the term "sustainable development" means different things to different people and organizations. The different concepts tend to reflect a variety of agendas, beliefs and conflicts; more than that, the exact meaning of the term is being discussed for more than 25 years. Disappointments and illusions refer to the social limits of growth which are impossible to reconcile with the global industrial production growth.

Moving forward, the vagueness of the term opens ample opportunities for "greenwashing"; for example, the term "green" was very often commercialized to justify unsustainable practices and activities. Many if not most of the activities that are in fact not sustainable, can appear as "green" misleading the population for all sorts of marketing tricks. An example of this are green approaches of airports and airplanes such as "EcoFly" or "Project Green Flights" (Pargman and Raghavan, 2014).

According to TerraChoice Environmental Marketing (in Dahl, 2010), although greenwashing is a concept known since the mid-1980s, its use has increased significantly in recent years because companies strove to meet the consumers' demand for greener products. On its third Greenwashing Report (2010) issued on the subject (in the United States and Canada), TerraChoice identified 4744 products making green claims, showing an increase of $73 \%$ by comparison to the company's second report (2009), $95.4 \%$ of those products being guilty of greenwashing. Among the multitude of green labels available today, only a few are recognized as highly reliable. Claudette Juska (in Dahl, 2010:6), a research specialist at Greenpeace, thinks that "people have become skeptical of any environmental claims. They don't know what's valid and what isn't, so they disregard most of them." Anyway, attaching the adjective sustainable to any type of activity - from construction to economic activities or ministries - cannot be suitable because it is hard to believe that all these activities are truly sustainable. He believes it is important to identify and accept the limitations of sustainability, in order to avoid losing the true sense of the term Marcuse (2006). 


\subsection{The Main Obstacles and Challenges on the Path of Change}

Regarding the barriers that intervene in the path of sustainability, Rogers et al. (2008) offer a more complex list of obstacles that make hard to achieve the goal of becoming a sustainable planet:

Terrorism. Worst case scenario concerning terrorism involves a situation in which a terrorist group will get nuclear weapons or other weapons of mass destruction;

Climate change. This is a more complex issue due to the lack of consensus on the effects they may experience in the next years;

Global food system. Lack of soil fertility is a problem faced by many countries. The use of chemicals is not a solution anymore because "the ground has become a junkie which needs chemicals as it's no longer able to produce on its own".

Globalization. It has many manifestations of unsustainable behavior. The best example is the "export" of waste and polluting industries to other countries, which globally is not a solution.

On the other hand, other opinions support the idea that population growth is the main obstacle to a sustainable society. Bartlett (2006) considers necessary to implement on a global scale, the family planning - and even reducing the aid granted to states that do not have sufficient measures in reducing national population.

Another aspect that needs to be taken into consideration is the awareness of the impact that corporations might have on sustainable development. Steger (2004) emphasized the importance of large corporations and their involvement in efforts that are truly sustainable. In order to demonstrate the magnitude of the power owned by corporations, he presented in his work, the results of a study according to which, the aggregate turnover of the top 200 corporations in the world exceeded the economies of all countries of the world minus the cumulative top 10.

Doing the same research but using the updated data, for 2015, we found that the situation has improved. Using the statistics published on fortune.com and worldbank.org, we cumulated the revenue of the top 200 biggest corporations in the world and compared it to the economies of all countries of the world minus the cumulative top 10 (based on a comparison of company revenue and country GDPs). We briefly present our research results as follows:

-Top 200 corporations sums 18.3 trillion $\$$ in revenue, representing $24.77 \%$ of the world GDP (compared to $27.5 \%$ in 1999 );

- The aggregate revenue of the top 500 corporations in the world (27.6 trillion \$) exceeded the economies of all countries of the world minus the cumulative top 10 (24.8 trillion $\$$ ).

- Top 500 corporations employ only a tiny fraction of the world's labor force $(1.97 \%)$.

Having as a starting point Anderson and Cavanagh's research (2000) for 1999, we made a comparison between top 100 economies in the world and for that, we updated the information until 2015 using the statistical data available on www.fortune.com and www.worldbank.org. As a result, in 1999, $51 \%$ of the 100 largest economies in the world was owned by corporations while in 2015 , the trend appears to be going in the reverse direction (66\% countries, 34\% corporations). Even if national economies won more power over the time, the fact that in 2015, 34\% of the top 100 economies of the world is owned by corporations, can be considered an alarming statistic.

In their research, Anderson and Cavanagh (2000) are bringing into question if these companies are truly providing what's good for the countries and global society. The conclusion of their research is that widespread trade and investment liberalization have contributed to a climate in which big corporations have registered increasing levels of economic and political power that are out of balance with the real benefits they provide to society.

The study presents results of a research conducted by Business Week magazine which revealed that between $72 \%$ and $82 \%$ of Americans believe that corporations have gained 
too much power over many aspects of their life and $74 \%$ agreed with Al Gore's criticism of "a wide range of large corporations, including "big tobacco, big oil, the big polluters, the pharmaceutical companies, the HMOs'" (Anderson and Cavanagh, 2000). The conclusion is that big companies have a lot of influence over government policy and policy-makers. This is just one of numerous statistics that clearly indicate that active engagement of corporations is essential if the world wants to achieve changes in the patterns of production and consumption or on domestic and international laws that will be needed to align the planet on the path of sustainability.

Sometimes, change is considered to be initiated by minorities or intellectual elite who run the risk of being pioneers. So it takes an impulse that can later cause chain reactions. In this way, people become aware of the problems they face and can seek solutions for them. Furthermore, Gorbachev (2006:160) draws attention to the people to exercise their voting power in the political establishment, which should be judged according to their facts, not their words. Therefore, he said, "we need a new Glasnost to inspire citizens to become actively involved in the struggle for a better future."

Meadows (2006), believes in the need for a sustainability revolution. Like the Industrial Revolution in the past, it will require decades or centuries to achieve completely, but according to the author, "Sustainability Revolution" has already begun.

\section{Conclusion}

There are a lot of other views regarding the sustainable development and its drawbacks and being such a complex matter, it may be the subject of a broader research. In conclusion, sustainable development is a mixture of many stories, actions, values and perspectives which require the capacity and availability to listen to others and leave aside established opinions. However, lack of information, confusion over cause and effect, no clear vision of sustainability, the underestimation of the impact that some stakeholders (such as corporations) might have on this matter, are only a few of the aspects that require more attention and which indicate shortcomings of our actions and attitudes towards sustainable development.

\section{References}

Anderson S., Cavanagh J. (2000). Top 200. The Rise of Corporate Global Power, Institute for Policy Studies, Washington.

Bartlett (2006). 'Reflections on sustainability, population growth, and the environment' in Keiner, M. (ed.) The Future of Sustainability, Springer, Dordrecht.

Badulescu A., Badulescu D., Bac, D., Șipoș-Gug S., (2014). 'Attitudes and intentions of business master students towards sustainable tourism and entrepreneurship', Amfiteatru Economic, vol. 16, no. 8, pp.891-905.

Badulescu, A (2004), Economia turismului, Editura Universităţii din Oradea, Oradea.

Bâc, D. (2008). 'A history of the concept of sustainable development: literature review' Annals of University of Oradea. Economic Sciences, vol.17, no.2, pp. 576-581.

Beckerman, W. (2002). A Poverty of Reason: Sustainable Development and Economic Growth, The Independent Institute, Oakland.

Dahl, R. (2010). 'Green Washing: Do You Know What You're Buying?'Environmental Health Perspect, vol. 118, no. 6, pp. 246-252.

Gorbachev, M. (2006). 'A New Glasnost for Global Sustainability', in Keiner, M. (ed.) The Future of Sustainability. Dordrecht: Springer.

Lomborg, B. (2001). The Skeptical Environmentalist: Measuring the Real State of the World, Cambridge: Cambridge University Press. 
Marcuse, P. (2006). 'Sustainability is Not Enough', in Keiner, M. (ed.) The Future of Sustainability. Dordrecht: Springer.

Meadows, D. (2006). Tools for the Transition to Sustainability', in Keiner, M. (ed.) The Future of Sustainability. Dordrecht: Springer.

Munasinghe, M. (2010). 'Addressing the Sustainable Development and Climate Change Challenges Together: Applying the Sustainomics Framework', Procedia Social and Behavioral Sciences, no. 41, pp. 6634-6640.

Munasinghe, M. (2007). 'Sustainomics and sustainable development”, [online], Available from: http://editors.eol.org/eoearth/wiki/ Sustainable_development\#Sustainable_development_triangle_and_balanced_viewpoint. [12.10.2016].

Pargman, D., Raghavan, B. (2014). Rethinking Sustainability in Computing: From Buzzword to Non-negotiable Limits, [Online], Available from: https://www1.icsi.berkeley.edu/ barath/papers/sustainability-nordichi14.pdf. [12.10.2016]. Robinson, J. (2004). 'Squaring the circle? Some thoughts on the idea of sustainable development', Ecological Economics, vol 48, no. 4.

Rogers, P., Jalal, K. Bozd, J. (2008). An Introduction to Sustainable Development, Oxford: Earthscan.

Rojanschi, V., Bran, F., Grigore, F., Ioan, I. (2006). Cuantificarea dezvoltării durabile, Bucuresti: Editura Economică.

Speth, J.G (2008). The Bridge at the End of the World, London: Yale Univ. Press.

Steger, U (2004). The Business of Sustainability, London: Palgrave Macmillan Publishers. World Health Organization (2003). Diet, Nutrition and Prevention of Chronic Deseases [Online], Available from: http://www.fao.org/docrep/005/AC911e/ ac911e05.htm. [19.01.2017].

The World Bank (2017). World Development Indicators, [online] Available from: http://data.worldbank.org/data-catalog/GDP-ranking-table [19.01.2017].

Fortune 500 (2016). [online] Available from: http://beta.fortune.com/fortune500/list. [19.01.2017].

UNEP (1972). Declaration of the United Nations Conference on the Human Environment, [online] Available from: http://www.unep.org/documents.multilingual/default.asp? documentid=97\&articleid=1503. [19.01.2017].

FAOSTAT (2017). Food Security Indicators, [online] Available from: http://www.fao.org/ faostat/en/\#data/FS. [18.01.2017].

\section{Bio-note}

Paula-Carmen Roșca, is Ph.D. student at University of Oradea, Faculty of Economics Sciences. Her research interests include general aspects of sustainable development and her main focus for the $\mathrm{PhD}$ research is corporate sustainability. 